Histologycally tumor revealed bland spindle-shaped cells with indistinct pale eosinophilic cytoplasm and small hyperchromatic oval nuclei, ring cell likes were also observed (Fig 2A and 2B), ploemorphism and mitotic features (Fig 2C and 2D). The tumor cells were embedded in a variably fibrous or myxoid stroma that tended to alternate in different areas of the tumor. Immunohistochemical analysis of the tumor cells revealed diffuse expression of vimentin, CD99 (Fig 2E) and CD117 (Fig 2F). Ewing sarcoma was diagnosed. The tumor was resistant to different kinds of therapy.

\section{DISCUSSION}

Primitive neuroectodermal tumors are in the Ewing's sarcoma family of tumors and are composed of small round cells, belong to a family of tumors that share clinic pathologic and molecular genetic features, including the characteristic chromosomal translocation that results in the fusion of the EWS gene on 22q12 to either the FLI1 gene on $11 \mathrm{q} 24$ or other ${ }^{2-4}$. One basic distinction is between primitive neuroectodermal tumors of the central nervous system (cPNETs) and primitive neuroectodermal tumors of the peripheral nervous system (pPNETs), which are clinicopathologically and genetically distinct ${ }^{3,4}$. Among the cPNETs including medulloblastoma, pineoblastoma, cerebral neuroblastoma, ependymoblastoma, medulloepithelioma, primary rhabdomyosarcoma, and atypical teratoid/rhabdoid tumor, whereas the pPNETs comprise the more differentiated end of a spectrum of neoplasms that include skeletal and extraskeletal Ewing's sarcoma. In most instances these entities may be differentiated by a panel of antibodies that should include those with low and high molecular weight cyto- keratins, epithelial membrane antigen, type IV collagen, ENE, sinatophysin, CD99, CD56, and S-100 protein ${ }^{3}$.

Appropriate treatment is based on a correct diagnosis, the surgical pathologist must be familiar both with basic characteristics of each of the numerous entities as well as the spectrum of morphologic features that each may display ${ }^{3,4}$.

\section{REFERENCES}

1. Paulussen M, Ahrens S, Braun-Munzinger G, et al. EICESS 92 (European Intergroup Cooperative Ewing's Sarcoma Study) preliminary results. Klin Padiatr 1999; 211:276-283.

2. Mazur MA, Gururangan S, Bridge JA, et al. Intracranial Ewing sarcoma. Pediatr Blood Cancer 2005; 45:850-856

3. Carvajal R, Meyers P. Ewing's sarcoma and primitive neuroectodermal family of tumors. Hematol Oncol Clin North Am 2005;19:501-525.

4. Verrill MW, Judson IR, Harmer CL, et al. Ewing's sarcoma and primitive neuroectodermal tumor in adults: are they different from Ewing's sarcoma and primitive neuroectodermal tumor in children? J Clin Oncol 1997;15:2611-2621.

\section{SARCOMA DE EWING TEMPORAL CEREBRAL PRIMÁRIO COM EXTENSÃO PARA O CRÂNIO}

'Unidad Académica de Medicina, Universidad Autónoma de Nayarit, México; ${ }^{2}$ Departamento de Neuropatología, Instituto Nacional de Neurología y Neurocirugía Manuel Velasco Suárez, México City, DF., México; ${ }^{3}$ Servicio de Neurología, Instituto Nacional de Neurología y Neurocirugía Manuel Velasco Suárez, México City, DF., México; ${ }^{4}$ Servicio de Neuroimagen, Instituto Nacional de Neurología y Neurocirugía Manuel Velasco Suárez, México City, DF., México; ${ }^{5}$ Service of Neuroimagen, National Institute of Neurology and Neurosurgery, México City, DF., México.

Support: Armstrong Fundation for all support that they gave to the student Claudia Martinez during this investigation.

Correspondence: Martha Lilia Tena Suck - Laboratorio de Neuropatología Experimental - Instituto Nacional de Neurología y Neurocirugía "Manuel Velasco Suárez" - Av. Insurgentes Sur 3788 Col. La Fama, Tlalpan - C.P. 14269 - México D.F. E-mail: tenasuck@yahoo.com.mx

Received 12 May 2010, received in final form 3 May 2011. Accepted 10 May 2011.

\title{
Isolated hypoglossal nerve palsy An unusual rare presentation in systemic lupus erythematosus
}

\author{
Paulo José Lorenzoni', Rosana H. Scola , Cláudia S.K. Kay , Felipe T.M. Novak', \\ Elaine H. Cardoso', Márcia R.R. Scalcon², Acir Rachid Filho², Lineu C. Werneck
}

Systemic lupus erythematosus (SLE) is an immunemediated disease of unknown etiology which can damage the peripheral and central nervous system ${ }^{1}$. Cranial nerves have rarely been involved in SLE's patients ${ }^{2,3}$. Isolated hypoglossal nerve palsy (HNP) was even rarer reported in patient with SLE .
We report a patient with SLE who presented with isolated HNP.

\section{CASE}

A 27-year-old woman presented with fever, alopecia, skin rash, photosensitivity, Raynaud's phenomenon, ar- 

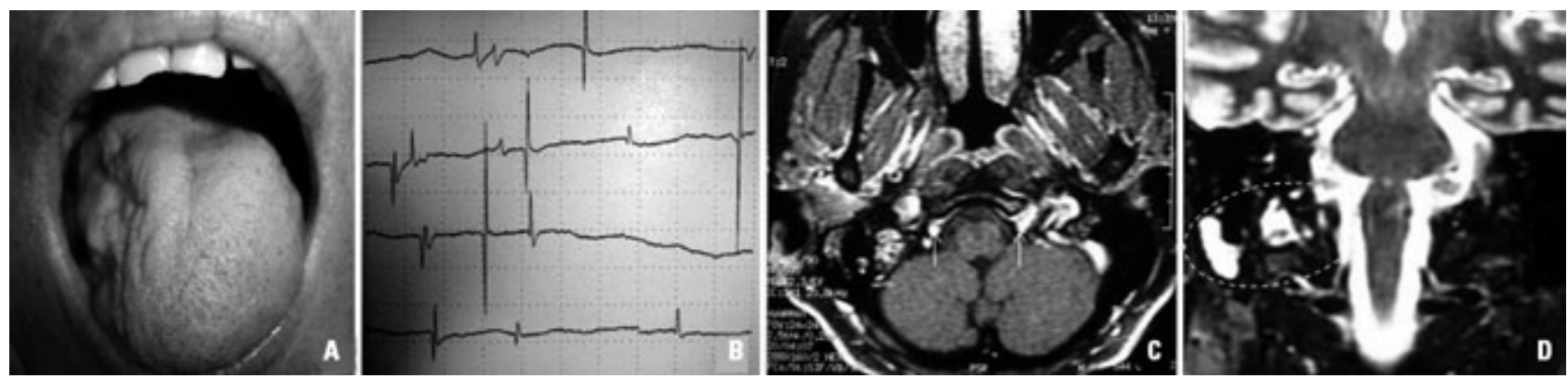

Figure. [A] The tongue is atrophied on the right. [B] Needle electromyography in tongue observed fibrillations potentials on the right side. [C] Brain magnetic resonance imaging revealed area of high signal on axial FLAIR-weighted images near right hypoglossal nerve canal (arrows). [D] Brain magnetic resonance imaging revealed area of high signal on coronal T2-weighted images in the right mastoid cells, lateral clivus region, and hypoglossal nerve canal (circle).

thritis, joint and muscle pain associated to lymphopenia and low complement levels. Antinuclear, anti-Sm, anti-DNA and anticardiolipin (IgG) antibodies were detectable. The diagnosis of SLE was made, and after treatment with hydroxychloroquine $(250 \mathrm{mg} /$ day), prednisone $(10 \mathrm{mg} /$ day), and methotrexate $(7.5 \mathrm{mg} /$ week $)$ her disease was controlled.

At 42 years of age, she developed a sudden onset of dysarthria with minor speech difficulty that was related to tongue immobility, and poorly articulated speech for lingual consonants. She later noted that her speech was slurred and her tongue deviated to the right when protruded. She denied trauma, cervical pain, episodes of aspiration (airway protection), exposure to drugs or toxic agents.

Cranial nerve examination showed asymmetrical tongue position at rest with atrophy and weakness in right side of her tongue (Fig A). The tongue deviated to the right when protruded (Fig A). She was also unable to fully protrude the right cheek against resistance using the tongue. Gag reflex, swallowing, taste and sensation of tongue and oropharynx were normal.

The investigation yielded the following results: fibrillations and positive wave potentials were observed in needle electromyography of tongue on the right (Fig B); brain magnetic resonance imaging revealed areas of high signal in the right mastoid cells, lateral clivus region and hypoglossal nerve canal (Fig C and D); and increased reactive $C$ protein $(1.66 \mathrm{mg} / \mathrm{dL}$; normal $<0.5 \mathrm{mg} / \mathrm{dL})$.

The SLE management with increase of prednisone $(60 \mathrm{mg} /$ day) controlled her disease and resulted in marked and progressive improvement of her symptoms and tongue paralyses (HNP) after few weeks.

All studies were done following informed consent.

\section{DISCUSSION}

Cranial neuropathies prevalence in SLE varies among different studies ranging between $2 \%$ and $7 \%^{2}$. In the majority of cases, cranial neuropathies are either multiple or occur in association with deficits in the ascending and descending pathways. Isolated cranial neuropathy is very rare and only described in anecdotal case reports and small case series ${ }^{3,5}$. This is the second case report of SLE complicated with isolated $\mathrm{HNP}^{4}$.

We believe that SLE predisposed our patient to develop isolated hypoglossal neuropathy, but the pathogenesis of cranial nerve palsy in SLE is unknown. In the first case reported, HNP followed fulminant acute pneumonitis in a SLE patient with kidney and pulmonary amyloidal deposit, suggesting that nerve palsy was a vascular phenomenon of $\mathrm{SLE}^{4}$. However, three theories have been suggested: auto-antibodies to neuronal antigens, ribosomes, and phospholipids either produced locally or having crossed an altered blood-brain barrier as well as blood-nerve barrier; vascular lesions (vasculitis or antiphospholipid antibodies mediated ischaemic/thrombotic vasculopathy); or inflammation related to local cytokine production ${ }^{1,2}$.

Although treatment of SLE associated with cranial nerve palsy remains empirical our patient showed improvement after adjustment of prednisone dose.

\section{REFERENCES}

1. Muscal E, Brey RB. Neurologic manifestations of systemic lupus erythematosus in children and adults. Neurol Clin 2010;28:61-73.

2. Bruns A, Meyer O. Neuropsychiatric manifestations of systemic lupus erythematosus. Joint Bone Spine 2006;73:639-645.

3. Saleh Z, Menassa J, Abbas O, Atweh S, Arayssi T. Cranial nerve VI palsy as a rare initial presentation of systemic lupus erythematosus: case report and review of the literature. Lupus 2010;19:201-205.

4. Chan CN, Li E, Lai FM, Pang JA. An unusual case of systemic lupus erythematosus with isolated hypoglossal nerve palsy, fulminant acute pneumonitis, and pulmonary amyloidosis. Ann Rheum Dis 1989;48:236-239.

5. Alves P. Imaging of hypoglossal nerve. Eur J Radiol 2010;74:368-377.

PARALISIA ISOLADA DO NERVO HIPOGLOSSO: UMA APRESENTAÇÃO RARA NO LUPUS ERITEMATOSO SISTÊMICO

Internal Medicine Department, Hospital de Clínicas, Universidade Federal do Paraná (UFPR), Curitiba PR, Brazil: 'Neurology Division,'2Rheumatology Division.

Correspondence: Rosana Herminia Scola - Serviço de Doenças Neuromusculares / Hospital de Clínicas da UFPR - R. General Carneiro 181 / $3^{\circ}$ andar - 80060900 Curitiba PR - Brasil. E-mail: scola@hc.ufpr.br

Received 20 April 2011. Accepted 1 June 2011. 